\title{
EL SISTEMA DE EDUCACIÓN ABIERTA Y A DISTANCIA DE LA UNIVERSIDAD NACIONAL DE MAR DEL PLATA. PASADO, PRESENTE Y UNA PROYECCIÓN A FUTURO
}

\author{
(THE OPEN AND DISTANCE EDUCATIONAL SYSTEM OF THE NATIONAL UNIVERSITY OF MAR \\ DEL PLATA. PAST, PRESENT AND A PROJECT FOR THE FUTURE)
}

Guillermina Oliva

Beatriz Graciela Banno

Universidad Nacional de Mar del Plata (Argentina)

\section{RESUMEN}

El Sistema de Educación Abierta y a Distancia de la UNMdP tiene más de veinte años de trayectoria. Innovador en sus orígenes, supo ganarse un lugar de reconocimiento que trasciende hoy las fronteras de la provincia de Buenos Aires, su límite geográfico original.

Este artículo supone un recorrido por su historia, una mirada crítica respecto de sus logros y asignaturas pendientes y, fundamentalmente, una comunicación intencional, a efectos de compartir su proyección futura.

Se organiza en seis apartados. Los tres primeros, de carácter más descriptivo, dan cuenta, respectivamente, del contexto de surgimiento, la inserción institucional y la estructura organizativa actual del sistema.

Los tres últimos, focalizan las concepciones de fundamento, las alternativas de mejora introducidas para el Área de Producción Didáctica y tres propuestas de transformación que en ella se originaron.

Palabras clave: identidad institucional, estructura organizativa, mediación crítica, producción didáctica, capacitación de equipos. 


\begin{abstract}
The Open and Distance Educational System of the UNMdP has been working for more than twenty years. Innovator from the beginning, it has managed to gain great recognition which nowadays surpasses the Buenos Aires border, its first geographical limit.

This article introduces a journey along its history, a critic view not only about its achivements but also its unresolved projects and, predominantly, a purposed communication in order to share its future schemes.

It is organized in six abstracts. The first three, which are more descriptive, attempt to depict the context in which the system was born, its institutional insertion and its current organization, respectively.

Finally the last three abstracts outline the foundation concepts, the possible amendments for the Didactic Production area and their three transformation proposals.
\end{abstract}

Key words: institutional identity, organizational structure, mediation, didactic production, trainings programmes.

\title{
CONTEXTO DE SURGIMIENTO Y DESARROLLO DEL SISTEMA DE EDUCACIÓN ABIERTA Y A DISTANCIA (SEAD) ${ }^{1}$
}

La Universidad Nacional de Mar del Plata crea su primer proyecto en el área de Educación a Distancia en el año 1984, convocando un grupo de profesionales jóvenes de las ciencias de la educación bajo la dirección del Dr. Gustavo Cirigliano. En 1986, se lo reformula, bajo el título de Proyecto Universidad Abierta.

El contexto de surgimiento de este proyecto está inserto, a nivel nacional, en el proceso de reinstauración democrática, que considera una necesidad de reivindicación histórica el ingreso de actores sociales que habían quedado fuera de la Universidad en la etapa de la dictadura militar (1976-1983).

En el nuevo escenario de la democratización educativa, a la necesidad de atender la dispersión geográfica se le suma el ingreso masivo a las universidades, generándose la necesidad institucional de promover la apertura en lo referente al acceso, promoción y acreditación: articulación con titulaciones previas, ampliación de la oferta educativa y reconocimiento de saberes, experiencias y competencias previas. 


\section{Propósitos institucionales de Universidad Abierta²}

Ampliar las oportunidades de educación universitaria a distintos sectores de la población, utilizando los recursos que brinda para ello la modalidad de educación a distancia.

Ofrecer carreras, cursos y/o propuestas de formación que, por su nivel, calidad y contenido, satisfagan reales necesidades emergentes de las demandas sociales y culturales de cada región.

Garantizar, a través de una concepción abierta de la educación, el acceso, permanencia y consecución exitosa de los estudios emprendidos a todos aquellos que, independientemente de su extracción socioeconómica, opten por realizar estudios universitarios.

Posibilitar que todos los alumnos, al concluir sus estudios, alcancen los máximos niveles de logro, acorde con los diversos aspectos que configuran una formación de calidad.

Contribuir al mejoramiento del hábitat y de la calidad de vida humana, especialmente en el ámbito regional en el que se esté operando.

Procurar la mayor optimización de los recursos humanos y materiales que se requieran para el desarrollo regional, así como la más adecuada administración de los mismos, de acuerdo con necesidades existentes.

Contribuir al desarrollo de conocimientos de relevancia social, cultural y científica.

Generar las condiciones necesarias para la concreción de los propósitos y acciones institucionales.

Generar y mantener en constante revisión crítica, metodologías de acción institucional orientadas a crear y afianzar las condiciones que se estimen necesarias para la concreción de los propósitos, hasta aquí enunciados.

La existencia institucional de este proyecto instala en los claustros universitarios la controversia entre educación de primera y educación de segunda. El cuerpo docente miraba con desconfianza esta propuesta de aprendizaje y cuestionaba fuertemente la posibilidad de mediatización de la enseñanza ${ }^{3}$.

El paradigma de intervención didáctica al que se adhería -sistema multimedialproponía el uso de medios impresos, encuentros presenciales, televisión, radio, audio y videocassettes... como superador de los módulos impresos y autosuficientes generalizados en la modalidad. 
La estrategia de combinación de estos medios, en concordancia con el tipo de aprendizaje esperado comenzaba a instalarse en las discusiones entre pedagogos y tecnólogos.

Durante la década de los 90 asistimos a la llegada de las nuevas tecnologías digitales. Su arribo al equipo técnico pedagógico fue lento y desigual, requiriendo otras formas de trabajo e instalando otras categorías de análisis a la hora de diseñar cursos y carreras: accesibilidad y conectividad.

Si históricamente la EaD había saltado fronteras de dispersión geográfica, disponibilidad de horarios, cuestiones de género, falta de escolarización formal, ahora tenía un nuevo desafío: la brecha digital que profundizaba aún más las diferencias sociales y económicas acentuadas durante los años 90 en la Argentina.

Paradójicamente aparece un nuevo destinatario de la modalidad, en su versión e-learning. Los cambios en el paradigma productivo y su impacto en el mercado de trabajo, genera la necesidad de actualización y formación continua en todas las áreas de competencia laboral: todas las profesiones tienen que incorporar en su desempeño conocimientos y técnicas de innovación y el uso de herramientas informáticas.

Se crea como consecuencia indirecta un gran mercado de la formación, donde las ofertas educativas compiten en cuanto a los tiempos de formación, a las facilitaciones tecnológicas que incorporan y a las acreditaciones que brindan. La educación a distancia se convierte en una respuesta adecuada. Actualmente nuestro sistema reconoce diferentes destinatarios, con características contextuales diversas, que acceden a nuestras propuestas con sus propias expectativas y demandas, para las cuales procuramos diseñar estrategias de intervención apropiadas.

\section{INSERCIÓN INSTITUCIONAL}

El SEAD ha tenido desde su inicio una vinculación directa con el Rectorado de la Universidad, dependiendo funcionalmente de su Secretaría Académica. Fue concebido como una unidad de servicios central, cuestión que no se ha modificado a través de los años.

Esta ubicación en la organización se traduce en la forma de trabajo para la generación de ofertas académicas. El diseño e implementación de cursos y carreras se realiza en forma coparticipada con las diferentes Unidades Académicas. 


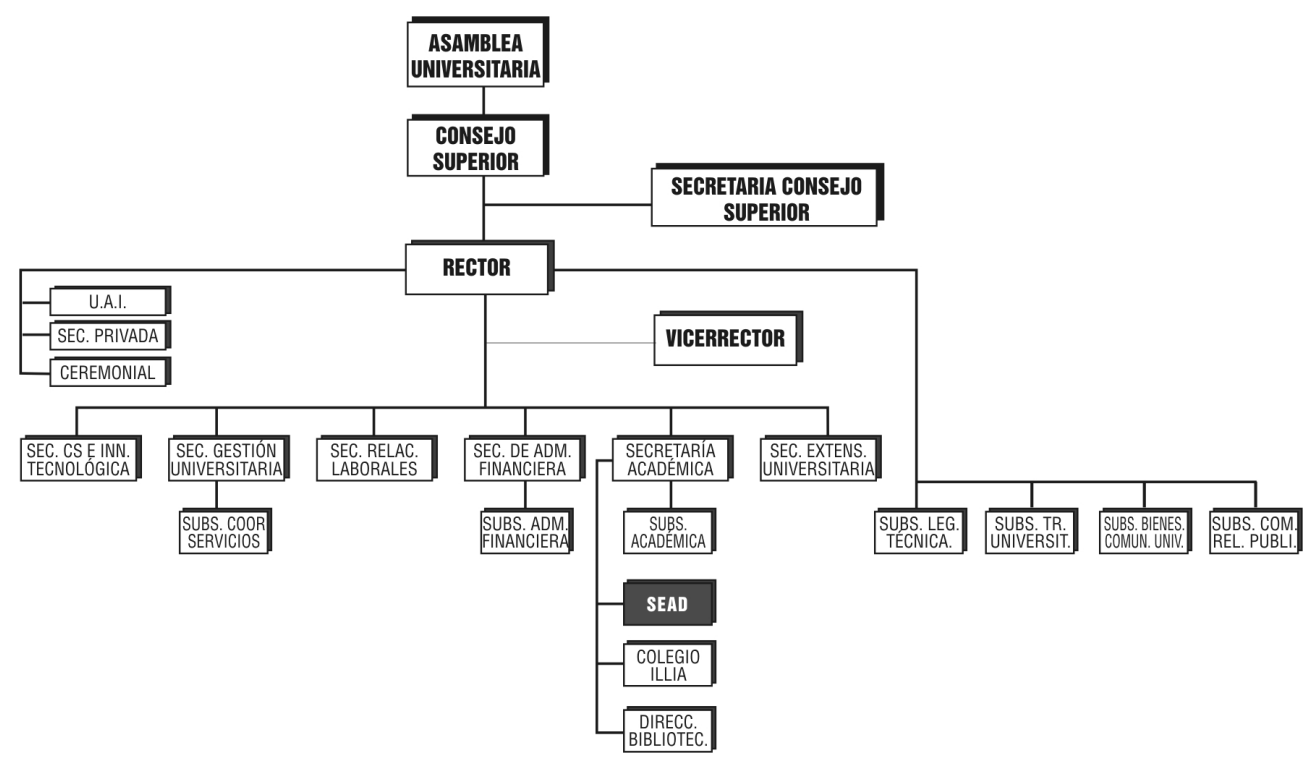

A través de diferentes normativas se ha ido regulando esta relación. Actualmente se inicia el trabajo conjunto con un estudio de factibilidad de la propuesta que abarca diferentes relevamientos de información, para describir las viabilidades -técnica, económica, política, tecnológica- y recomendar al Consejo Académico de la Facultad que corresponda, las mejores condiciones curriculares para su realización.

En el siguiente listado indicamos algunas de las propuestas educativas implementadas con cada Unidad Académica4:

\begin{tabular}{|l|l|l|}
\hline \multicolumn{1}{|c|}{ Unidad Académica } & $\begin{array}{c}\text { Cursos de postgrado } \\
\text { y/o extensión }\end{array}$ & Carreras de grado \\
\hline $\begin{array}{l}\text { Facultad de Ciencias } \\
\text { Agrarias }\end{array}$ & & $\begin{array}{l}\text { Curso de nivelación para } \\
\text { aspirantes a Ingreso a la } \\
\text { Facultad 2003 }\end{array}$ \\
\hline Facultad de Psicología & Bioética y salud 2001 & \\
\hline
\end{tabular}




\begin{tabular}{|c|c|c|}
\hline Unidad Académica & $\begin{array}{l}\text { Cursos de postgrado } \\
\text { y/o extensión }\end{array}$ & Carreras de grado \\
\hline $\begin{array}{l}\text { Facultad de Ciencias } \\
\text { Exactas y Naturales }\end{array}$ & $\begin{array}{l}\text { Actualización en } \\
\text { genética } 1990 \\
\text { Educación ambiental } \\
1995 \\
\text { Apicultura } 1997 \\
\text { Ciencias naturales para } \\
\text { nivel inicial } 1997 \\
\text { Acuicultura: una } \\
\text { propuesta para } \\
\text { la generación de } \\
\text { microemprendimientos } \\
\text { 1999 } \\
\text { Laboratorio virtual de } \\
\text { fisicoquímica } 2006\end{array}$ & \\
\hline $\begin{array}{l}\text { Facultad de Ciencias de } \\
\text { la Salud }\end{array}$ & $\begin{array}{l}\text { Atención en enfermería } \\
\text { para el paciente } \\
\text { diabético } 1993 \\
\text { Atención en enfermería } \\
\text { para el paciente } \\
\text { politraumatizado } 1994 \\
\text { Intoxicaciones por } \\
\text { plaguicidas 2003 } \\
\text { Identidad, conflicto } \\
\text { y salud en el ámbito } \\
\text { laboral } 2004\end{array}$ & $\begin{array}{l}\text { Ciclo superior de la } \\
\text { Licenciatura en Servicio } \\
\text { Social } 1998\end{array}$ \\
\hline Facultad de Derecho & $\begin{array}{l}\text { Aspectos filosóficos de la } \\
\text { bioética } 1997 \\
\text { Bioética y derecho } 2000 \\
\text { Propiedad horizontal } \\
\text { y administración de } \\
\text { consorcios } 2003 \\
\text { Procedimiento tributario } \\
\text { aplicado } 2004\end{array}$ & $\begin{array}{l}\text { Abogacía (primer tramo } \\
\text { de la carrera) } 1999\end{array}$ \\
\hline
\end{tabular}


El Sistema de Educación Abierta y a Distancia de la Universidad Nacional de Mar del Plata...

\begin{tabular}{|c|c|c|}
\hline Unidad Académica & $\begin{array}{c}\text { Cursos de postgrado } \\
\text { y/o extensión }\end{array}$ & Carreras de grado \\
\hline $\begin{array}{l}\text { Facultad de Ciencias } \\
\text { Económicas y Sociales }\end{array}$ & $\begin{array}{l}\text { Capacitación en servicio } \\
\text { para funcionarios } \\
\text { públicos municipales } \\
1989 \\
\text { Formación de guías } \\
\text { turísticos 1990 } \\
\text { Ley Orgánica Municipal } \\
1995 \\
\text { Alternativas turísticas } \\
\text { regionales 1996 } \\
\text { Comercio exterior } 1998\end{array}$ & $\begin{array}{l}\text { Tecnicatura en } \\
\text { Administración Pública } \\
1998\end{array}$ \\
\hline $\begin{array}{l}\text { Facultad de } \\
\text { Humanidades }\end{array}$ & $\begin{array}{l}\text { Capacitación en servicio } \\
\text { para personal de } \\
\text { bibliotecas } 1989 \\
\text { Palabra en texto } 1994 \\
\text { Comunicación y texto } \\
1996 \\
\text { Metodología de la } \\
\text { investigación científica } \\
2001\end{array}$ & $\begin{array}{l}\text { Bibliotecario Escolar } \\
1994\end{array}$ \\
\hline Facultad de Arquitectura & & $\begin{array}{l}\text { Tecnicatura en Gestión } \\
\text { Cultural } 2000\end{array}$ \\
\hline Facultad de Ingeniería & $\begin{array}{l}\text { Normas ISO } 14000 \\
2002 \\
\text { Gestión de } \\
\text { Mantenimiento en } \\
\text { empresas } 2005\end{array}$ & $\begin{array}{l}\text { Curso de Ingreso a la } \\
\text { Facultad } 2003\end{array}$ \\
\hline
\end{tabular}

También se han realizado acciones educativas con otros organismos e instituciones a partir de convenios interinstitucionales, como por ejemplo: 
El Sistema de Educación Abierta y a Distancia de la Universidad Nacional de Mar del Plata...

\begin{tabular}{|l|l|c|}
\hline \multicolumn{1}{|c|}{ Org. / Instituciones } & \multicolumn{1}{c|}{ Oferta } & año \\
\hline $\begin{array}{l}\text { Ministerio de Salud Provincia Buenos } \\
\text { Aires }\end{array}$ & $\begin{array}{l}\text { Tecnicatura en Laboratorio de } \\
\text { Análisis Clínico }\end{array}$ & 2000 \\
\hline $\begin{array}{l}\text { Secretaria de Salud - Programa por } \\
\text { Amor a la Vida- Municipalidad de } \\
\text { Gral. Pueyrredon }\end{array}$ & $\begin{array}{l}\text { Prevención en el uso indebido de } \\
\text { drogas }\end{array}$ & 1993 \\
\hline Instituto Nacional de Epidemiología & Toxicología clínica & 1995 \\
\hline $\begin{array}{l}\text { Secretaria de acción cooperativa } \\
\text { - Municipalidad de Gral. Pueyrredon }\end{array}$ & $\begin{array}{l}\text { Una forma de hacer ... capacitación } \\
\text { en cooperativismo para adultos en } \\
\text { proceso de alfabetización }\end{array}$ & 1992 \\
\hline
\end{tabular}

A partir del año 2001, de acuerdo a requerimientos de formación en el área de diferentes grupos de docentes, el equipo del SEAD ha diseñado el programa denominado La educación a distancia y semipresencial: una particular forma de encuentro, que comprende tres cursos relacionados ${ }^{5}$ :

- Bases conceptuales y modelos organizativos en EaD. La producción de un proyecto de educación a distancia.

- La gestión de proyectos en educación a distancia.

\section{ESTRUCTURA ORGANIZATIVA}

En el documento fundacional quedan establecidas las bases para que el sistema de Universidad Abierta funcione desde una Sede Central, ubicada en la ciudad de Mar del Plata y dependiente de la Secretaría Académica del Rectorado de la Universidad, relacionada con una primera red de Centros Regionales de Educación Abierta y Permanente (CREAP), distribuidos en la provincia de Buenos Aires.

Cada Centro Regional surge de un convenio de coparticipación entre la Universidad y el Municipio de la localidad, o en su defecto, con instituciones referentes para la implementación de las ofertas educativas. En cada Centro Regional se encuentra un Coordinador local, y un Asistente Educativo que es docente de la Universidad y responsable de garantizar la implementación de cursos y carreras en las condiciones técnico pedagógico que se diseñan en la Sede Central. 


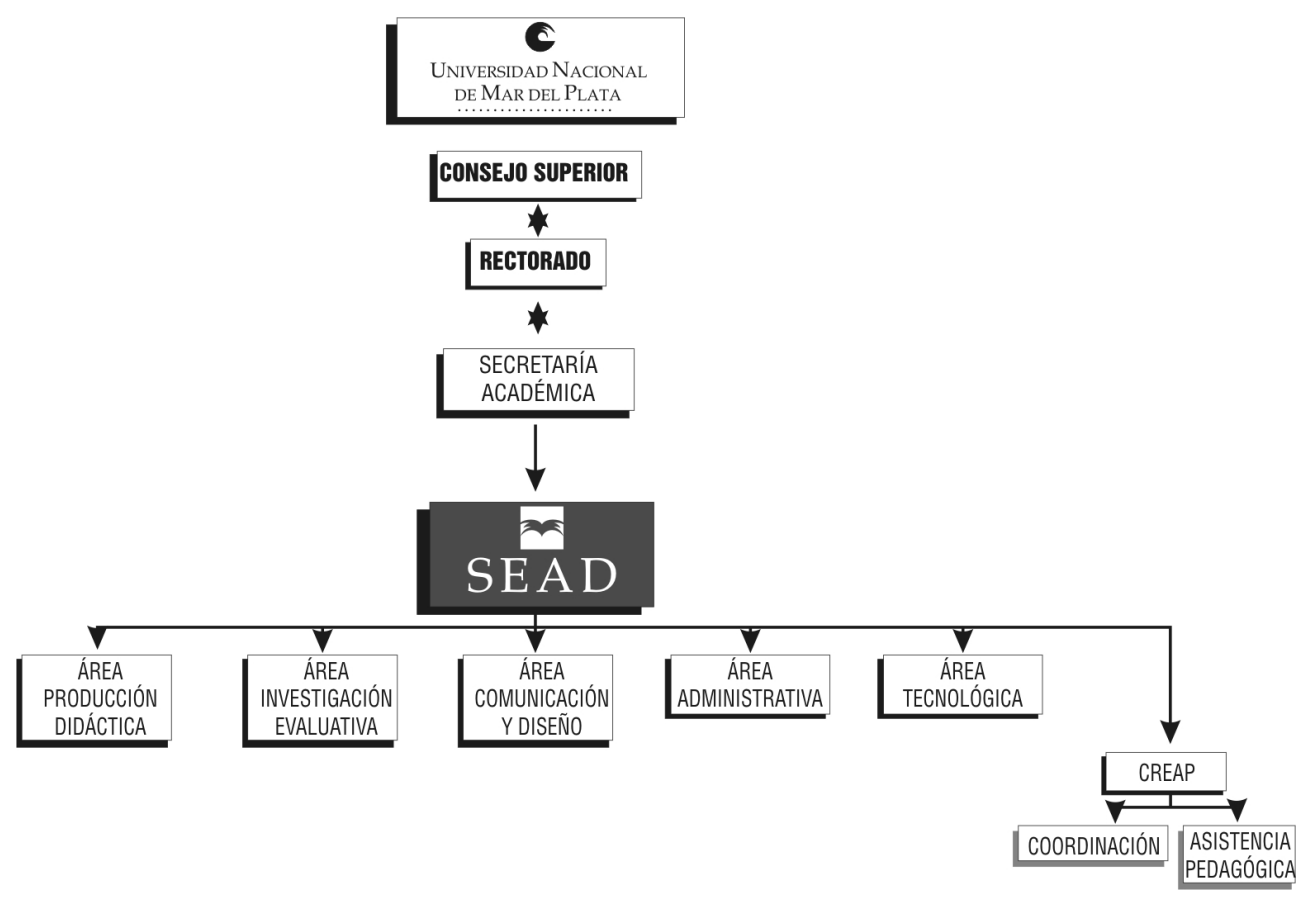

\section{Sede central}

En la Sede Central se encuentran las autoridades de gestión, el equipo técnicopedagógico, el equipo de diseño y tratamiento gráfico de imágenes, el equipo de evaluación, el centro de cómputos, el área de TV-vídeo y la infraestructura administrativa de apoyo. La especificidad académica del equipo permanente está comprendida en el área de pedagogía y didáctica. Para cada una de las carreras o cursos se conforman equipos de producción incorporando especialistas del campo de conocimiento que corresponda como especialistas en el contenido, que generalmente son docentes provenientes de las distintas unidades académicas o de otros organismos.

Esta interdisciplinariedad supone, en todo el proceso, el respeto por la autonomía académica de los docentes que se desempeñan como especialistas en los contenidos disciplinares específicos. A través de esta integración es posible consolidar ofertas en las que el soporte académico se centra en la Unidad que le da origen, mientras que los procedimientos pedagógicos y técnicos, propios de la gestión a distancia, son responsabilidad de los docentes del SEAD. 
La Sede Central reconoce una estructura constituida por una Dirección, cinco áreas de organización de la tarea -Producción Didáctica, Comunicación y Diseño, Investigación evaluativa, Administrativa y Tecnológica- en las que se distribuyen los equipos técnico-pedagógicos y administrativos, según funciones que se detallan a continuación en el siguiente cuadro:

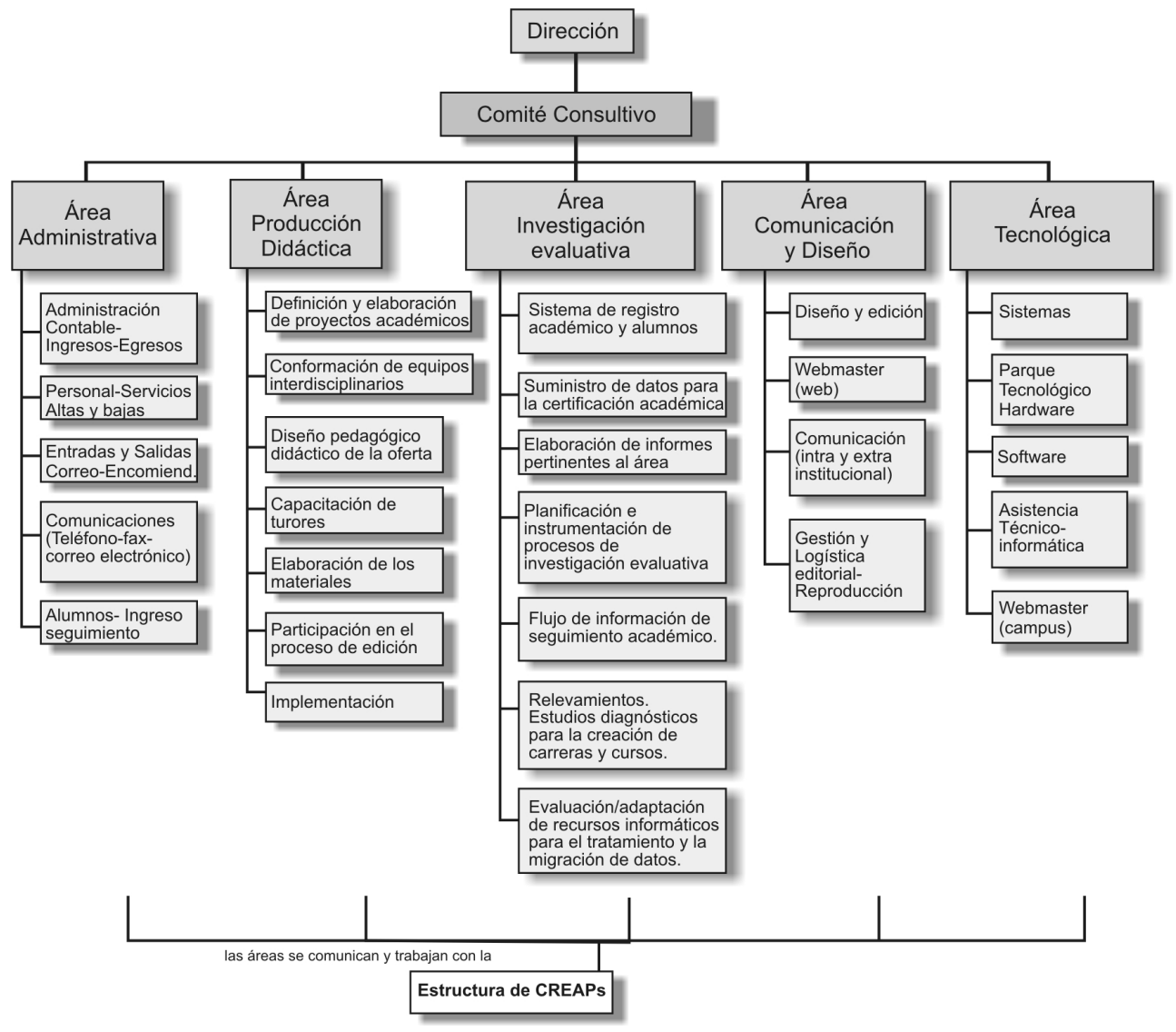

\section{Centros Regionales de Educación Abierta y Permanente (CREAP)}

Los Centros Regionales de Educación Abierta y Permanente (CREAP) constituyen una red de centros de apoyo, de nivel universitario. Funcionan como unidades de recursos educativos, para las actividades de formación, actualización y capacitación y, simultáneamente, como centros de difusión del conocimiento y la cultura a nivel local y regional. 
Estos centros surgen a partir de la concreción de convenios de coparticipación entre la Universidad, los Municipios u organismos no gubernamentales. En ellos se desempeñan: el Asistente Educativo -cuya función es la de tutor pedagógicodesignado por la Universidad y el Coordinador de CREAP, figura político administrativa, designada por el Municipio o contraparte del convenio. En el convenio suscripto entre la Universidad y el Municipio se especifican las responsabilidades de las partes.

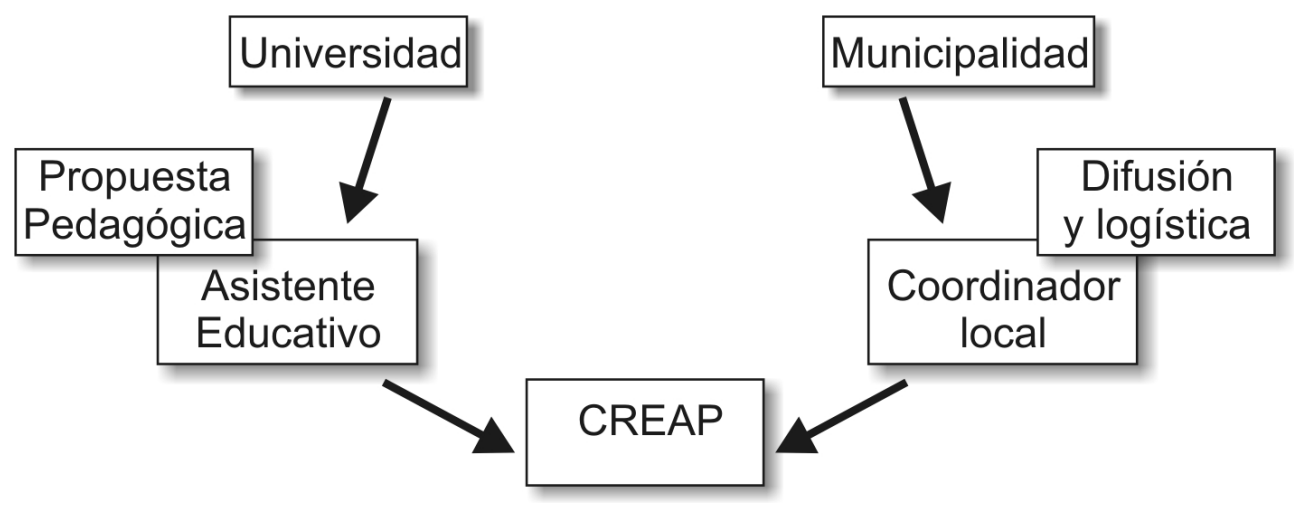

De él surge que la Administración Municipal es la encargada de proporcionar la infraestructura mínima necesaria para desarrollar las acciones del Centro y designar el Coordinador -figura político-administrativa- cuya función será garantizar el acceso del estudiante a los servicios que brinda la Universidad, asegurando su buen funcionamiento y constituyéndose así en interlocutor válido entre la Universidad y el Municipio.

Queda a cargo de la Universidad la designación del Asistente Educativo, que es un docente residente en la localidad donde está ubicado el C.R.E.A.P. quien vehiculiza las propuestas de formación y capacitación elaboradas por el equipo académicopedagógico de Sede Central.

El área de influencia del SEAD se concentró en un principio en los municipios aledaños al de Gral. Pueyrredon, abarcando paulatinamente toda la Provincia de Buenos Aires y superando, posteriormente, los límites provinciales en un área significativa del país y del extranjero, a través de convenios institucionales. 


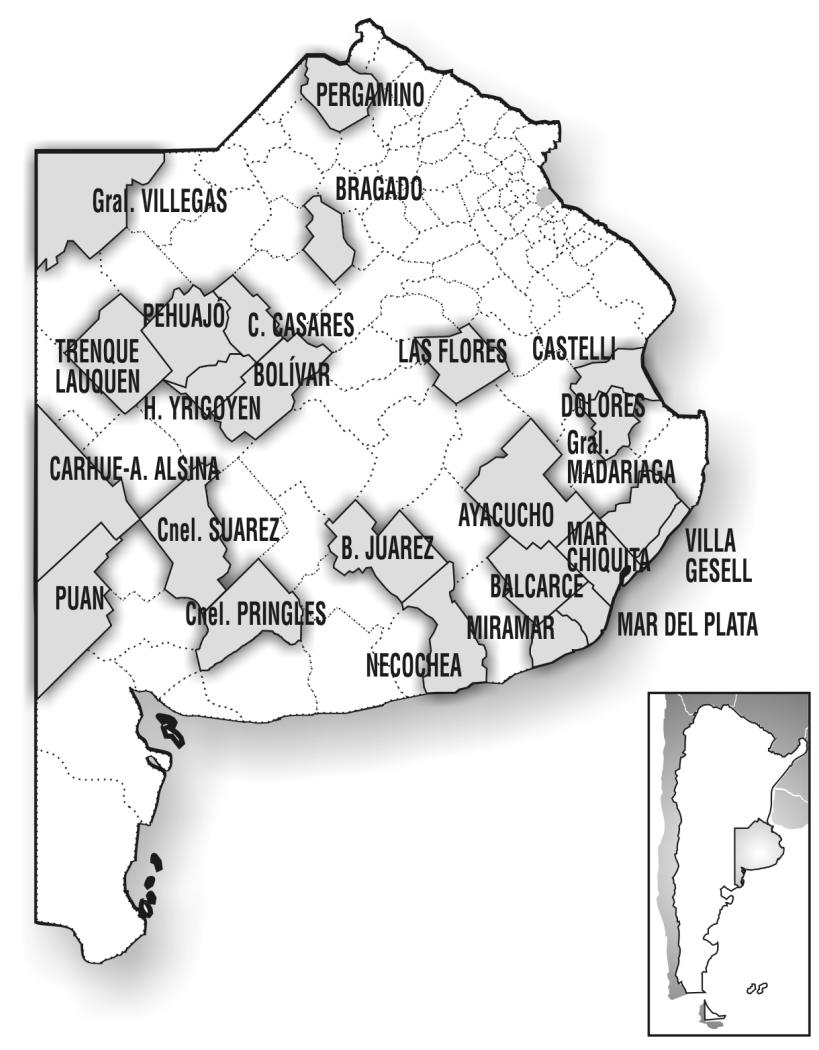

Los CREAP son verdaderos vasos comunicantes entre la universidad y la sociedad, cuyas actividades generan un positivo impacto tanto en el ámbito cultural, como científico-tecnológico.

\section{FUNDAMENTOS DE UN MODELO PEDAGÓGICO PARA EL DISEÑO DE PRÁCTICAS EDUCATIVAS A DISTANCIA}

Y la cosa de educar no es una esencia o idea arquetípica. Es una historia de complejas prácticas sociales ... Carlos Cullen

En este apartado proponemos al lector un recorrido por las definiciones que están a la base del SEAD y que constituyen los fundamentos que inspiran las decisiones de tipo operativo. Lo hacemos con la intención de transparentar aquellos componentes 
de la cultura institucional, no siempre visibles, y que al momento actual los actores institucionales reconocemos como producto de la construcción colectiva y la trayectoria recorrida.

Un sistema de educación a distancia es una organización político pedagógica que ofrece instancias de formación a través de diversos medios y soportes. Cada una de ellas es una propuesta intencional de transmisión de determinados saberes -lo que supone un recorte también deliberado en el campo del conocimiento- y es en este sentido en el que debemos asumir la fuerza definitoria con la que este hecho se impone y tiñe todo el proceso pedagógico: proponemos intencionalmente la apropiación de unos saberes por parte de nuestros destinatarios y allí es donde quedamos definitivamente posicionados como sujetos de la mediación entre unos y otros; esto es, entre esa porción del conocimiento y sus destinatarios.

Por esta razón es prioridad en el SEAD asumir que la concepción de cada una de sus ofertas de educación a distancia supone un posicionamiento paradigmático con su consecuente intencionalidad axiológica y teleológica. Sin esta premisa estaríamos contribuyendo a la expansión de la industria maquilladora de la educación (Buchbinder y Rajapogal, 1996) ${ }^{6}$.

Optar por esto último implica, desde nuestro punto de vista, equivocar el rumbo de la educación a distancia, algo así como seguir ciegamente el canto de sirena que nos dice que una infraestructura de alta tecnología garantiza el éxito de la enseñanza a distancia. El éxito de cualquier proceso de enseñanza es la calidad de los aprendizajes que promueve y ésta, si bien no tiene garantías aseguradas, cuenta, podríamos decir, con ciertos reaseguros. Uno de ellos somos nosotros, los docentes asumidos como mediadores críticos y críticos de la mediación. Desprendemos de las consideraciones hechas hasta aquí los requisitos de una mediación crítica:

- Establecer verdadera comunicación. Más allá del medio que la efectivice, la comunicación será personal y democrática y esto supone la igualdad de oportunidades en la generación de los mensajes.

- Propiciar el trabajo independiente y el desarrollo paulatino de las competencias propias del aprendizaje autónomo.

- Garantizar sesiones de tutoría como verdaderas interacciones socráticas, (Buchbinder y Rajapogal, 1996).

- Incentivar, en la medida de lo posible, la confrontación de opiniones y la construcción solidaria y cooperativa del conocimiento entre pares.

- Formular los criterios, procedimientos e instrumentos de evaluación sobre la base de fundamentos acordes con este enfoque. 


\section{Alternativas de gestión de las ofertas y estrategias metodológicas}

Actualmente son dos las alternativas de gestión de las ofertas educativas, aquellas que adoptan una modalidad semipresencial y las que se brindan exclusivamente a distancia. Las decisiones que hacen optar por una u otra modalidad responden, fundamentalmente, a las características particulares dela oferta y, consecuentemente, a las que definen el perfil del público destinatario.

Estos distintos modos de acción implican estrategias diferentes para cada caso, no obstante ambas responden a la concepción de aprendizaje que el SEAD sustenta que sumariamente puede sintetizarse en los postulados siguientes:

- Es una construcción que hace un sujeto en interacción cognitiva y afectiva con otros sujetos y con los objetos de conocimiento.

- En la situación particular del aprendizaje en contexto educativo formal, el proceso se encuentra generalmente mediado por la persona del docente y contextuado por una propuesta curricular específica que concreta un proyecto político pedagógico.

Esta fuerte impronta de los fundamentos epistemológicos y pedagógicos hace que, cualesquiera sea la modalidad y los medios y soportes que vehiculicen la comunicación, se apelará siempre a los saberes previamente construidos por los estudiantes y a las interacciones múltiples que garanticen aproximaciones, paulatinas pero crecientes en ajuste, a los objetos de conocimiento que se espera que éstos construyan.

Consecuentemente, el hilo conductor de las decisiones metodológicas lo constituye el propósito de brindar a los estudiantes, conjuntamente con los contenidos seleccionados las orientaciones y ayudas necesarias para despertar la conciencia de su propia intervención en el proceso de aprendizaje.

En este sentido procuramos superar la falsa dicotomía entre enseñar contenidos y enseñar a aprender con una apuesta clara por enseñar a aprender los contenidos dado que sostenemos que la enseñanza de las estrategias, conducente a mayor autonomía en el desempeño del estudiante, ha de realizarse en el contexto específico donde deberán ser luego desplegadas por el alumno. Este contexto situacional está determinado por la especificidad epistemológica, lógica y metodológica de la disciplina y, más restrictivamente aún, por los objetivos que para el particular se han formulado. 
En palabras de Carles Monereo (1999), se trata de una concepción de la intervención didáctica basada en la reflexión metacognitiva.

En una línea similar Sergio Antonio Sandoval (2003) destaca que, los resultados de una educación en la que está ausente la enseñanza del pensamiento (EDP), se manifiestan constantemente en las características de un aprendizaje memorístico, repetitivo, y en no pocos casos, dramáticamente sin sentido.

\section{Acerca de los medios y materiales propuestos y su valor estratégico}

\section{Con soporte impreso}

El empleo de material impreso fue el principal soporte en las primeras etapas del sistema. Actualmente se reserva sólo para aquellas ofertas en las que se considera estrictamente necesario. En esos casos se conciben y diseñan para que sean portadores de las orientaciones didácticas favorecedoras de las interacciones, cognitivas y afectivas, del estudiante con las fuentes teóricas -de modo de garantizar su comprensión y apropiación significativas-. Por otra parte, tales intervenciones, procuran estimular la adquisición creciente de competencias de aplicación práctica en el campo del saber específico. Asimismo se estimulan las interacciones con pares y docentes de manera de favorecer los intercambios productivos propios del aprendizaje cooperativo y colaborativo.

\section{Algunas características propias de estos materiales}

En general adoptan una estructura pensada para responder a los tres requerimientos básicos en el proceso de estudio:

- Adquisición de los conceptos estructurantes.

- Reelaboración conceptual en la práctica a través de variadas actividades, planteo de cuestiones, resolución de ejercicios y problemas.

- Desarrollo de una visión personal -por parte del estudiante- de sus modos de proceder frente a las exigencias del aprendizaje y de su capacidad para controlar sus propias actitudes, disposiciones y desempeño general. 


\section{Con soporte digital}

Dentro de ellos es de uso frecuente el CD-Rom con una intencionalidad didáctica similar a la señalada para el material impreso. Se emplea frecuentemente en la mayoría de las ofertas con excepción de aquellas que se vehiculizan por el campus virtual.

Este material ofrece ventajas interesantes por sobre el impreso, en relación con los costos de edición, a la vez que registra amplio espectro de accesibilidad en la población destino. Es menester aquí volver, sin ánimo de reiteración, al principio fundante de democratización de la educación. Éste no podría cumplirse si el sistema no atendiera a las condiciones de acceso -por parte de la población destinataria- a los medios elegidos para vehiculizar una determinada oferta.

Como ejemplo vale mencionar algunos de los principales requisitos técnicos y didácticos contemplados -dentro de la estrategia de intervención- en la concepción y diseño del CD-Rom editado para los aspirantes a ingreso a la Facultad de Ciencias Agrarias (cohortes 2004 a 2007). Esta población, particularmente necesitada de acompañamiento y sostén, que demandó mayor atención en la elaboración de los materiales (módulo impreso y CD-Rom) manifestó luego alto grado de compatibilidad con él7.

El CD reúne las orientaciones metodológicas para cada una de las tres asignaturas constitutivas del curso que, si bien mantienen la originalidad e impronta propia de cada disciplina, responden a normas comunes en cuanto a la elección de criterios de navegación fácil con empleo de estructura poco profunda.

Desde el punto de vista didáctico destaca la sección propuestas del docente en la que el estudiante encuentra intervenciones puntuales para orientar el análisis de los desarrollos teóricos y la resolución de los ejercicios y problemas del módulo impreso. Tales intervenciones -tendientes a arrojar más luz sobre los procedimientos que debe paulatinamente incorporar para alcanzar un abordaje comprensivo superador del desempeño memorístico y repetitivo- son producto del trabajo mancomunado entre contenidista y pedagogo, referido en otra parte de este artículo.

En este sentido se hace hincapié en las habilidades básicas del pensamiento y la relación que ellas tienen en la comprensión del contenido propuesto, se procura orientar la resolución ofreciendo modelos de análisis que partan del reconocimiento, por parte del estudiante, de la finalidad de la tarea solicitada y que den apertura a distintas líneas de resolución. Una intervención puntual está destinada a que el estudiante reconozca errores u obstáculos en sus planteamientos y tenga la oportunidad de rectificarlos analítica y significativamente.

Se espera favorecer así la autorregulación ofreciendo un punto de apoyo pero a la vez promoviendo un paulatino despegue de esa ayuda. 


\section{El campus virtual}

El hecho de concentrar en una plataforma de e-learning las diferentes instancias de concreción de la intervención didáctica -materiales, tutorías, comunicación entre pares- genera el desafío de realizar un diseño pedagógico que incorpore las potencialidades propias del medio e imprima una nueva dinámica a la gestión de un curso o asignatura con modalidad a distancia. Para su desarrollo y funcionamiento posibilita una integración flexible de los contenidos y el seguimiento, y monitoreo del trabajo y progreso de los alumnos.

Desde la administración y gestión académica del curso se cuenta con una herramienta de gestión de usuarios que posibilita la configuración de perfiles con diferentes atribuciones y derechos de acceso, como así también la elaboración de estadísticas e informes sobre el trabajo y logros de aprendizaje de los estudiantes.

Las posibilidades en edición de contenidos en diferentes formatos de archivo, incluye la incorporación de gráfica con alta calidad de visualización -fotografías color/ imágenes animadas-, con mayor cantidad de ejemplos ilustrativos alternativos y recorridos hipertextuales superadores de la secuencia única de lectura, más la capacidad de reedición y actualización.

Herramientas tales como Noticias, Sitios de Interés o Archivos para compartir, permite incorporar informaciones, problemáticas y ampliaciones bibliográficas a la medida de los requerimientos que van surgiendo en cada grupo.

Como ejemplo referiremos el caso del curso de extensión universitaria Acuicultura: una propuesta para la generación de microemprendimientos ${ }^{8}$. En él se decidió la incorporación de diferentes formatos de archivo, dentro de la plataforma, de acuerdo a la función específica del documento. A saber: 
Micrositio: la elección de publicar los contenidos de los ejes temáticos como micrositio, es decir, un sitio independiente de la estructura de la plataforma, se debió a la posibilidad de mantener la autonomía para realizar las siguientes acciones:

- Definir libremente el diseño de navegación, en relación con la estructura interna del curso.

- Integrar hipertextualmente imágenes animadas, sonidos y textos.

- Diferenciar con una imagen visual propia la temática del curso.

- Conservar el óptimo procesamiento gráfico de la información que caracteriza los materiales educativos producidos por el SEAD.

- Poseer similitud con el formato de nuestro espacio en el sitio web de la Universidad Nacional de Mar del Plata.

- $\quad$ www.mdp.edu.ar/uabierta/acui/index.htm

Documentos de Texto: utilizamos formularios de texto para la realización de las Actividades Integradoras y Trabajos Prácticos, en los que el estudiante remite el documento con su respuesta en los campos de texto activos.

Presentación Multimedia para el Eje Temático 4: Especies Cultivables, se decidió crear un fichero de las diferentes especies, en formato de presentación power point, para publicarlo de forma que el estudiante pueda descargarlo de la web y guardarlo en su propio rígido. De esta manera se convierte en una herramienta diaria de consulta que se irá ampliando con los nuevos aportes de los alumnos. Dicho archivo lo hemos comprimido para acelerar el proceso de descarga, utilizando el más común de los programas comprensores, Winzip, ya que es de distribución gratuita y se puede descargar desde su sitio Web (Banno; Posat; Vallarino; Mallo, 2004).

La potencialidad comunicacional de la plataforma hace referencia tanto a cuestiones relacionadas con la tarea de aprendizaje -notificación de fechas de entrega, avisos grupales o individuales de cambios, pedidos de aclaración o ampliación de información, clarificación de consignas, entrega de trabajos- como a cuestiones de proceso grupal correspondientes al acompañamiento y sostenimiento del participante -presentaciones personales, incorporación de fotos, verificación y comunicación de los niveles de progreso de cada estudiante- generándose a partir de tales interacciones una red vincular de inestimable valor en la modalidad.

Para ello se cuenta con las herramientas de comunicación disponibles: calendario, correo electrónico interno, foros de discusión y control de progreso del estudiante. La doble vertiente, tecnológica -mensajería, calendario, foros de discusión, chat- y metodológica -perfil del tutor, moderación de los foros, textualización de la presencia social, análisis comparativo de rendimientos- facilita una dinámica de trabajo tutorial de características particulares. 
La posibilidad de configurar perfiles docentes con distintas atribuciones y permisos de acceso, permite distribuir funciones de acuerdo al perfil que requiere cada rol dentro del equipo de trabajo de la gestión académica. También a los estudiantes se les puede asignar o restringir accesos para incorporar archivos, sugerir temas de discusión, publicar noticias, ver calificaciones de sus compañeros, entre otros.

Siguiendo el caso del curso de Acuicultura podemos señalar las siguientes cuestiones con respecto a la función tutorial:

Las tutorías se mantienen como canales abiertos de comunicación a lo largo de la implementación de todo el curso, tanto dentro como fuera de la plataforma. Contamos con tutores de dos tipos:

Tutora pedagógica: atiende consultas con respecto a las orientaciones generales para el inicio del trabajo a distancia, acceso a los diferentes materiales disponibles, al uso de las herramientas. Recuerda fechas de entrega de trabajos e instrucciones para su envío.

Dispone de correo electrónico dentro y fuera de la plataforma y atiende posibles consultas telefónicas en la Sede Central.

Dado su perfil de formación cumple funciones de administrador tomando decisiones en la selección de las herramientas disponibles para el curso, en el diseño pedagógico de su utilización y en la orientación general de las intervenciones docentes.

Tutores académicos: cumplen este rol los profesores que han desarrollado los contenidos del curso y que están a cargo de la evaluación de los participantes. Son consultores en todas aquellas cuestiones relativas al desarrollo de los temas y sus aspectos técnicos específicos. Son moderadores de los foros de discusión, que se generan a partir de una problemática determinada y por un determinado tiempo. Evalúan todos los trabajos que presentan los estudiantes y publican -en Calificaciones- los respectivos resultados con las apreciaciones y sugerencias que a cada uno corresponda.

El sostenimiento grupal lo realizan a partir de las intervenciones en foros, mensajería interna, control de actividad de los participantes

\section{EL ÁREA DE PRODUCCIÓN DIDÁCTICA, NÚCLEO VITAL EN LA GENERACIÓN DE PROPUESTAS}

Se inicia este apartado con una referencia sumaria a las recomendaciones que para la organización y funcionamiento del área emanaron de la coordinación a principios de 2006. Si bien muchos de los aspectos mencionados corresponden al 
modo habitual de funcionamiento del sistema, otros suponen la introducción de modificaciones en consecución de metas de optimización. El sentido de su inclusión está dado porque anticipan los proyectos concretos que se concibieron y desarrollaron y cuya referencia se realiza en el punto siguiente.

La producción de materiales didácticos en el SEAD ha estado en todas sus etapas asociada a la figura del procesador pedagógico, diseñador instruccional o especialista en educación a distancia y semipresencial, según se ha denominado. Adoptaremos aquí el término diseñador didáctico o expresión similar postergando el controvertido análisis que desde los posicionamientos paradigmáticos cada expresión amerita.

Los procedimientos implicados en la planeación y ejecución de un curso a distancia son complejos, ya que traen consigo las decisiones de nivel didáctico acompañadas por las decisiones a nivel tecnológico.

El sistema cuenta con un equipo técnico pedagógico, con alto grado de especializaciones vinculadas a la modalidad. Esta condición, a la hora de constituir los equipos de cada unidad de trabajo, redunda directamente sobre la calidad educativa del producto. En la práctica cotidiana se prioriza la calidad académica, la potencialidad de la estrategia didáctica y la vinculación con el destinatario.

\section{Ejes de organización de la tarea}

Se identifican como ejes vertebradores en el área el trabajo en equipo y el circuito de producción, éste último reconoce a su vez cuatro aspectos medulares. Sucintamente pueden referirse al:

- Trabajo en equipo

- Circuito de producción

Aspectos a lo que se refieren: organizativos, normativos, financieros y tecnológicos.

\section{Trabajo en equipo con los diseñadores didácticos}

El éxito de un trabajo en equipo ha de atribuirse, entre otras variables, a la definición de metas claras con respecto a la tarea; a la responsabilidad compartida en la realización de actividades conjuntas; a la posibilidad, en suma, de compartir 
decisiones y liderazgo, y de evaluar, con criterios consensuados, los resultados obtenidos.

Es por ello que, desde la vigencia de la nueva estructura organizativa por áreas, la coordinación del Área de Producción Didáctica ha propuesto:

- La designación de referentes claves en la vinculación con las Facultades

- La redistribución del personal del área en grupos por proyectos que facilitan la especialización de los recursos internos y permiten un mayor aprovechamiento de los tiempos de producción. Es ejemplo de este tipo de organización la agrupación por nivel: grado, postgrado, formación continua, capacitación docente ... dado que cada una responde a normativas especificas por facultad y/o jurisdicción

- Recuperación de una dinámica de reuniones y agenda de trabajo en equipo.

\section{Circuito de producción}

A continuación se presenta un índice esquemático ${ }^{9}$ conteniendo aquellas acciones constitutivas del proceso de planeación de un curso. Se ha intentado dar un sentido de orden a las acciones para facilitar las conexiones entre las diferentes instancias del proceso, ubicar claramente funciones y tareas entre los componentes de la organización, establecer cronogramas de trabajo y fomentar la responsabilidad del trabajo en equipo.

1- Atención de la demanda

1.1. Definición de características de la oferta

1.2. Matrícula esperada

1.3. Acuerdos intra/Inter institucionales

2- Conformación del equipo de producción $\left(^{*}\right)$

2.1. Selección de docentes y técnicos que van a participar

2.2. Contratación $y / o$ asignación de funciones

2.3. Inducción a la modalidad $\left(^{*}\right)$

3- Diseño pedagógico-didáctico $(*)$

3.1. Formulación de objetivos $\left(^{*}\right)$

3.2. Selección, organización y secuenciación de contenidos $(*)$ 
3.3. Definición de estrategias didácticas, medios y materiales $(*)$

3.4. Diseño de evaluación integral del curso $\left(^{*}\right)$

3.5. Financiamiento y presupuesto

4 - Producción e implementación

4.1. Edición

4.2. Reproducción de materiales

5- Gestión de la implementación

5.1. Comunicación y difusión

5.2. Inscripción

5.3. Facturación / distribución del material

5.4. Ejecución, seguimiento y evaluación del curso $(*)$

5.5. Acreditación

5.6. Evaluación de la propuesta y elaboración de informes

La conformación del equipo de producción puede estar definida previamente pero en todos los casos es necesario evaluar la puesta a punto de las competencias de sus integrantes de acuerdo con sus funciones específicas. Éstas son:

- Diseño instruccional.

- Elaboración de materiales en el soporte elegido.

- Entrenamiento de tutores y asistentes técnicos.

El proceso de diseño pedagógico-didáctico del curso completa la primera etapa de factibilidad de la oferta, circunscribiendo los alcances educativos, ponderando los recursos necesarios para producción de materiales y costos de implementación.

Una vez conformado el grupo de destinatarios es menester garantizar las condiciones metodológicas y tecnológicas de implementación de la propuesta: sistemas de atención al estudiante (tutorías), sostenimiento técnico de los recursos tecnológicos utilizados, recolección de información para procesos evaluativos, entre otros. Llegado el momento de la acreditación, el registro claro y actualizado de la información administrativa y de desempeño es un requisito primordial para iniciar el correspondiente circuito de certificación.

A continuación se puntualizan algunas cuestiones nodales en el diseño e implementación de una estrategia de intervención educativa con modalidad a distancia. El estilo de enseñanza y los resultados de aprendizaje esperados, serán 
particulares de cada experiencia, pero no podrán faltar definiciones con respecto al ambiente de aprendizaje, los materiales didácticos, el sistema y perfil de las tutorías y la interacción entre estudiantes.

- Ambiente de aprendizaje adecuado, utilizando nuevas tecnologías e interfases que favorezcan la atención del estudiante desde su propio contexto situacional, a partir de la adecuación y ajuste de la intervención diseñada según el perfil de destinatario potencial.

- Materiales didácticos: pertinentes, novedosos, atractivos, estimulantes... y que incorporen elementos curriculares y recursos que por su simbología y estrategias de abordaje favorezcan el desarrollo de habilidades cognitivas y metacognitivas en el destinatario.

- Tutoría: el trabajo de atención tutorial representa una gran parte del sostenimiento del estudiante a distancia. Su acompañamiento se evidencia a través de la resolución de tareas, en el abordaje del material instruccional y en la creación de presencia social a través de los medios de interacción.

- Interacción entre los estudiantes: no sólo permite la socio-construcción de conocimientos sino que representa una red de vinculación muy importante para desarrollar el sentido de pertenencia a una comunidad educativa.

Estos principios se desagregan en forma más detallada en el punto 4 Fundamentos de un modelo pedagógico para el diseño de prácticas educativas a distancia.

\section{Aspectos organizativos}

- Cada equipo de producción por curso o asignatura estará compuesto por el/los especialistas en contenido, el diseñador de comunicación visual y el diseñador didáctico, y tendrá a su cargo el diseño pedagógico-didáctico de los proyectos.

- Las tareas relacionadas con la gestión de la implementación -seguimiento y evaluación-serán diseñadas también en acuerdo al plan didáctico, pudiéndose acordar con los expertos en el contenido el tipo de acompañamiento pedagógico necesario para la misma. 
El Sistema de Educación Abierta y a Distancia de la Universidad Nacional de Mar del Plata...

- El equipo de producción colaborará con el Área de Comunicación para el diseño de la estrategia de comunicación y difusión, facilitando referencias específicas.

\section{Aspectos tecnológicos}

- En la elección de los formatos para editar los materiales educativos, se analizarán las condiciones institucionales de producción -en forma conjunta con el Área de Comunicación- y las condiciones de accesibilidad del público objetivo, desde la doble vertiente metodológica y tecnológica.

- Es deseable en esta etapa del sistema el fortalecimiento del recurso existente de campus virtual a través de estrategias que permitan el trabajo colaborativo con docentes para su utilización y óptimo aprovechamiento de su potencialidad.

- Continuar con la producción de impresos y CD-Rom multimedia, cuando sea pertinente a la estrategia didáctica.

- Evaluar alternativas de incorporación de otras propuestas tecnológicas.

\section{Aspectos normativos}

Definición de los requerimientos de producción e implementación de las propuestas en cuanto a:

- Normativa y reglamentaciones por Facultad y/o jurisdicción para la aprobación y acreditación de la oferta académica.

- Definición del rol requerido a los Asistentes Educativos u otros facilitadores, según funciones.

\section{Aspectos financieros}

Concertar la disponibilidad de recursos para la definición de medios y materiales: la factibilidad financiera para la edición, reproducción y distribución de materiales 
deberá estar acordada con la unidad académica o quien sea responsable de la ejecución presupuestaria.

\section{Aspectos administrativos}

Se necesita contar con el apoyo del Área Administrativa en todas las etapas de producción para facilitar el acceso a insumos y procedimientos.

De acuerdo con el esquema de trabajo hasta aquí explicitado, a comienzos del año 2006, el equipo de producción didáctica se abocó a la formulación de tres proyectos de capacitación de sus agentes. Uno de ellos dirigido al personal de Sede Central y los otros dos, en forma articulada, a los asistentes educativos de los CREAP.

Por ser ésta una experiencia reciente que conjuga las más destacadas fortalezas que el sistema logró consolidar es que se le otorga, en este artículo, un espacio preferencial como propuestas de innovación y mejora de su dinámica organizativa. Por ello se ofrece a continuación en forma sumaria las circunstancias que le dieron origen, las notas distintivas y las líneas de acción prospectiva para el bienio 2007 $-2008$.

TRES PROPUESTAS DE FORTALECIMIENTO DE LOS EQUIPOS DE TRABAJO

\section{Diagnosis, reflexión y propuestas de acción}

Desde su creación a la fecha el sistema atravesó diferentes etapas que supusieron tanto su consolidación y expansión como momentos críticos de retracción cuyo impacto se hizo sentir fuertemente en la vinculación de la Sede Central con los Centros Regionales y sus actores.

Por otra parte comenzaba a hacerse perentoria la urgente necesidad de capacitar a todo el personal en el uso del campus virtual. Si bien el sistema contaba con esta herramienta desde 2004 se vehiculizaban, a través de ella, sólo algunas ofertas. Tales circunstancias motivaron el análisis pormenorizado de la situación y la reflexión compartida entre responsables de distintas áreas que culminó en la concepción y ejecución de las propuestas antes mencionadas. 


\section{Debilidades y fortalezas en tiempos de crisis}

Si la Universidad Argentina sufrió en los últimos años los embates de las políticas de ajuste -situación que alcanzó la vida universitaria en todos sus campos de acciónel Servicio de Educación Abierta y a Distancia de la UNMdP se vio particularmente afectado por haber tenido que enfrentar, además, las contradicciones de la política interna.

La estructura de CREAP, en este panorama, fue tal vez la más afectada. Su figura principal, el Asistente Educativo, se vio desdibujada, y objeto de controversias dado que al contar el SEAD con un sitio web y su propia plataforma llegó a plantearse, desde algunos sectores de gobierno de la universidad, que el sistema podía prescindir de él.

No fue ajena a esta decisión la evaluación negativa que, en algunos casos, daba cuenta de intervenciones desajustadas, poco competentes, de los asistentes. Las condiciones de trabajo, ganadas por la inestabilidad, impactaron desfavorablemente en la cantidad y calidad de la tarea de estos agentes. Muchos de ellos renunciaron al sistema y fueron reemplazados por personal que no reunía experiencia en la modalidad y al que tampoco se le brindó la instancia, que en su momento había capacitado a la primera camada de asistentes, El curso-taller de formación y capacitación del Educador Abierto ${ }^{10}$.

No obstante, el sistema y sus actores habían ganado la inestimable experiencia que le brindaban sus casi dos décadas de presencia en la región como referente de la educación a distancia. De ellos había salido fortalecido en sus convicciones de fundamento, en sus principios de procedimiento y había aprendido a operar con una regla de oro, esto es, en estrecha y verdadera interacción solidaria entre fundamentos, medios y acciones incorporando la estructura tecnológica de soporte -ganada por los avances de última generación- sin poner en riesgo la entidad epistemológico pedagógica de sus ofertas de enseñanza.

Tal ensamble encontraría su mejor expresión a partir de la conjunción de propuestas cuyos componentes centrales -diseño didáctico, producción de materiales, gestión del aprendizaje autónomo a través del sistema de tutorías- se vehiculizarían en el campus virtual. Para ello se requería tanto la urgente capacitación del personal de Sede Central en el uso de tal herramienta como la recuperación de la figura del asistente educativo como agente comprometido del sistema, promotor experto de procesos de aprendizaje y gestor comunitario. 
En estas circunstancias surgen:

- Programa de capacitación en el uso del campus virtual.

- Espacio Enlace CREAP.

- Programa de fortalecimiento, redimensionamiento y actualización del rol de Asistente Educativo del SEAD.

\section{Programa de capacitación en el uso de campus virtual}

Concebido y desarrollado desde el Área de Producción Didáctica con apoyo del Área de Comunicación y Diseño, se implementa a partir de la cogestión del Sistema de Educación Abierta y a Distancia y ADUM (Agremiación Docente Universitaria Marplatense) como curso gratuito del Programa de Capacitación Docente que la entidad gremial desarrolla.

Se realizan dos ediciones. La primera dirigida en forma preferencial al personal del SEAD y extensivo a la comunidad docente de la universidad. En esta oportunidad se previeron dos niveles de dificultad: un nivel inicial y un nivel avanzado dirigido especialmente al personal del sistema que ya contaba con experiencia en la gestión de ofertas a través del Campus. En la segunda versión se desarrolló sólo el nivel inicial. Se explicitan a continuación algunos aspectos destacados de esta experiencia.

\section{Fundamentación}

El Sistema de Educación Abierta y a Distancia (SEAD) de la UNMdP ha incorporado el uso del campus virtual $e$-ducativa desde hace poco más de dos años. Paulatinamente fueron implementándose, en ese entorno, algunas de sus ofertas. Es posible establecer en la proyección institucional un incremento en la utilización de la plataforma que requerirá del dominio experto de todas sus funcionalidades y posibilidades por parte, no sólo de su personal docente y técnico, sino también de los docentes de las distintas Unidades Académicas con quienes se diseñan y ejecutan las ofertas de enseñanza.

Por otra parte, es posible otorgar valor diagnóstico a la manifestación creciente de interés en conocer y aplicar la plataforma, por parte de los docentes que, en carácter de especialistas de contenido, han estado y están vinculados al SEAD.

Ha de considerarse, también, que los entornos virtuales de aprendizaje son potentes espacios formativos en la medida que estén atravesados por los principios 
éticos y pedagógico - didácticos propios de la enseñanza universitaria de espíritu democrático y rigor académico.

La iniciación en el conocimiento técnico y procedimientos de aplicación práctica del campus virtual, por parte de los cursantes, favorecerá la introducción de intervenciones mediadas en sus prácticas de enseñanza.

Los fundamentos teóricos -tanto científicos como pedagógicos- unidos al conocimiento práctico, impactarán positivamente en las principales decisiones metodológicas, particularmente en aquellos aspectos que hacen a una intervención didáctica más ajustada a los ambientes de aprendizaje virtuales, entre ellos:

- Formas más apropiadas de organización de los contenidos: lineal, jerárquica, en red.

- Estrategias didácticas de mayor pertinencia: trabajo individual, en grupo, autónomo, guiado.

- Uso de las herramientas de comunicación sincrónica y asincrónica.

- Criterios y procedimientos de evaluación de los aprendizajes.

Estas circunstancias brindan sólida justificación al curso que aquí se presenta cuya intencionalidad rectora se expresa en el propósito y los objetivos que a continuación se detallan.

\section{Propósito}

- Brindar a los docentes de la UNMdP un espacio formativo y de capacitación que les permita administrar sus propios cursos en el aula virtual.

\section{Objetivos}

- Reconocer todas las funcionalidades y posibilidades que ofrece la plataforma e-ducativa para su aplicación a propuestas pedagógicas.

- Debatir casos específicos en relación con los perfiles de administrador, coordinador, profesor y/o tutor.

- Desarrollar, de acuerdo con los conocimientos adquiridos, una propuesta personal adecuada a sus necesidades de enseñanza.

- Contenidos.

- Encuadre didáctico del trabajo docente en un campus virtual. 
- Administración: definición de grupos y usuarios.

- Contenidos: archivos, sitios, noticias, calendario.

- Comunicación: agenda, foros, correo interno, chat.

- Evaluación: pruebas y libreta de calificaciones.

\section{Propuesta Pedagógica}

De acuerdo con la modalidad semipresencial adoptada para su implementación se desarrollaron dos jornadas presenciales y un período entre encuentros basado en el trabajo independiente del cursante, con tutoría virtual.

Durante los encuentros presenciales se apeló a la organización propia del taller. Esto supuso dos tipos diferentes de comunicación didáctica que se fueron alternando de acuerdo con los objetivos y temario propuestos y las necesidades particulares de los destinatarios:

- Intervención teórica, por parte de los docentes responsables;

- Ejecución de actividades de aplicación práctica, por parte de los cursantes, quienes trabajaron en forma individual o por parejas en cada uno de los equipos de PC bajo el asesoramiento y la orientación de los docentes.

\section{Evaluación - Condiciones de acreditación}

- Asistencia y participación en los dos encuentros presenciales.

- Realización de un trabajo práctico: desarrollo de una propuesta concreta de enseñanza utilizando herramientas de la plataforma e-ducativa.

\section{Criterios de evaluación}

- Ajuste de la propuesta a lo solicitado;

- Factibilidad de implementación;

- Pertinencia: objetivos - contenidos - destinatarios.

Cabe destacar que el primero de los tópicos propuestos referido al encuadre didáctico del trabajo docente en el campus virtual estuvo a cargo de una docente del equipo de producción en su carácter de pedagoga especialista en tecnología educativa ${ }^{11}$. Los restantes tópicos fueron dictados por ingenieros especialistas en el desarrollo de plataformas de la empresa prestataria. 
Cada edición del curso se dictó en dos jornadas intensivas, de ocho horas cada una, distanciadas por un período entre encuentros de quince días. Esta distribución horaria respondió a la necesidad de contar con un tiempo suficiente para que el cursante ejercite y resuelva las actividades propuestas. Para ello se brindó la posibilidad de realizar tutorías vía correo electrónico.

\section{Impacto de la propuesta}

En sus dos ediciones el curso alcanzó a más de sesenta docentes y en ambas oportunidades la demanda superó el cupo, impuesto por la capacidad del aula/ laboratorio y la relación docente/alumno -variables de rigor- dado el tipo particular de aprendizaje de procedimientos prácticos, ejecutables de acuerdo con estrategias de tipo algorítmico.

La evaluación de impacto de esta propuesta tiene indudablemente dos dimensiones de acuerdo con las dos poblaciones atendidas: por un lado el personal docente y técnico del SEAD y por otro los docentes de la universidad, algunos de los cuales están o estuvieron vinculados al sistema como especialistas en contenido. Aquí se hará referencia sólo al primero de los dos grupos referidos lo que supone circunscribir la mirada al impacto del curso al interior del sistema.

Como el curso de capacitación contemplaba como requisito de acreditación la formulación de una propuesta didáctica de ejecución a través del campus virtual, de hecho todas las presentadas y acreditadas -hasta el momento veinticuatro- suponen un impacto positivo tanto para el sistema como para la universidad. Dentro de ellas se dará particular atención a la denominada Enlace CREAP cuyos aspectos particulares desarrollaremos en el apartado siguiente.

\section{Enlace CREAP un espacio de comunicación y encuentro entre Sede Central y Centros Regionales}

Este proyecto surge para cubrir el requisito de acreditación del Curso de Capacitación para el uso de campus virtual. Es concebido e implementado conjuntamente por Raúl Poggi, Coordinador del Área de Comunicación y Diseño y Guillermina Oliva, responsable del Programa de fortalecimiento, redimensionamiento y actualización del rol de Asistente Educativo del SEAD.

Ambas propuestas quedan, a partir de la creación del espacio Enlace, estrechamente vinculadas dado que, las primeras etapas de sensibilización y 
sondeo de necesidades particulares de formación del programa para asistentes, se vehiculizaron a través de él.

Esto responde al criterio de no imponer desde la sede ofertas de actualización, sino, por el contrario, consensuar y negociar con los destinatarios los espacios formativos. Ganar la confianza, la disposición favorable, la apertura a una verdadera comunicación multidireccional son los objetivos prioritarios que se propone alcanzar con la creación de este nuevo espacio.

Asimismo, está prevista para principios de 2007 una prueba piloto, esto es, el desarrollo de un recorte del programa de fortalecimiento del rol de asistente educativo, vehiculizado de igual forma aprovechando las líneas de comunicación abiertas en este espacio.

Como logros colaterales, pero no de menor importancia, se espera un primer acercamiento, por parte de los destinatarios, al desarrollo de las destrezas necesarias como usuarios de la plataforma.

\section{Fundamentación}

Enlace CREAP se encuadra en una política de revalorización de los Centros Regionales, como espacio institucional, y de la figura del Asistente Educativo, como uno de los pilares del funcionamiento del mismo.

\section{Propósitos}

- Fortalecer las comunicaciones entre los Centros Regionales de Educación Abierta y Permanente y la Sede Central.

- Promover las consultas e intercambios de información entre los Asistentes Educativos los Coordinadores y equipos de Sede.

\section{Propuesta de intervención}

La aplicación elegida para esta forma de trabajo corresponde -dentro de las posibilidades que brinda el Campus- a la descripta como Educación a distancia, teniendo en cuenta la utilización y aprovechamiento de todas sus herramientas: temas, contactos, archivos, foros de discusión, calendario, correo interno y FAQs. 
Estas herramientas favorecen y agilizan las diversas actividades que se realizan para la gestión, orientación y seguimiento de los estudiantes del sistema, así como también para la actualización y capacitación permanente de los actores involucrados.

El ambiente promueve el intercambio de opiniones, la circulación de información a través de un correo interno, la carga y descarga de archivos, el acceso a material especializado y otras acciones que paulatinamente se irán incorporando en la medida de las necesidades impuestas por los distintos contextos y espacios de formación.

\section{Primeros logros obtenidos}

Desde la apertura del espacio virtual Enlace CREAP, al momento de escribir esta comunicación, ha transcurrido un mes. Si bien este breve período resulta escaso para desprender una evaluación de su impacto, es posible adelantar algunos resultados.

Las comunicaciones con los asistentes se han agilizado. El flujo de información ha aumentado considerablemente y fundamentalmente, las opiniones recibidas dan cuenta de un óptimo recibimiento por parte de sus destinatarios directos. Los mensajes recibidos manifiestan acuerdo con la intencionalidad de la propuesta y, por sobre todo, la satisfacción de sentirse revalorizados, tenidos en cuenta.

Es de esperar, que este promisorio comienzo continúe con igual entusiasmo el año entrante y sirva al logro de su intención rectora: recuperar, profesionalizar y optimizar los Centros Regionales y, por ende la figura del asistente educativo. Esto favorecerá el impulso y mejora, no sólo de las acciones hacia el interior del sistema; sino también de las que puedan generarse como actividades de extensión y gestión de espacios culturales en su zona de influencia. Programa de fortalecimiento, redimensionamiento y actualización del rol de Asistente Educativo del SEAD.

\section{Fundamentación}

El programa propone la actualización y capacitación, tanto pedagógica como tecnológica y administrativa, de los Asistentes Educativos, enfatizando su estatus de docentes universitarios, para hacer converger sus líneas directrices en el fortalecimiento del rol, objetivo que requiere, por un lado, una construcción identitaria y, por otro, una adjudicación externa con respaldo institucional. 
Por esta razón el programa centra sus esfuerzos no sólo en la actualización y adquisición de conocimientos de orden científico y técnico sino, fundamentalmente, en el trabajo reflexivo y autorreflexivo del destinatario con miras a instalar en la población destino el debate de los problemas propios de la enseñanza universitaria, en general y de la enseñanza a distancia, en particular, con una apuesta fuerte a la resignificación de los saberes adquiridos y al desarrollo creciente de un desempeño autónomo, riguroso en sus fundamentos, estratégico en las decisiones y crítico en las valoraciones.

Por otra parte, y en relación con aquellas definiciones que hacen a los fundamentos epistemológicos y científicos, el programa se posiciona en el marco referencial teórico de la Pedagogía como ciencia social crítico propositiva y de la Didáctica que, con similar enfoque, enfrenta la problemática de la enseñanza, en general, y de la enseñanza universitaria, en particular. Responde, asimismo, a los enfoques más recientes de la enseñanza a distancia, dentro de una línea crítica que, sin desconocer el inestimable aporte de las tecnologías de última generación, posiciona a éstas al servicio de los fundamentos y principios pedagógicos. Pretende, en consecuencia, el abordaje de los contenidos constitutivos de cada componente -didáctico, tecnológico y administrativo- mediante un proceso dialéctico de deconstrucción-reconstrucción que favorezca el impacto positivo en el desempeño de las funciones específicas de los destinatarios.

\section{Propósito}

Favorecer la creación de ambientes de aprendizaje -virtuales y presenciales- para la reflexión crítica, el intercambio fructífero y la construcción individual y colectiva de los saberes teórico-prácticos que garanticen el ejercicio idóneo del rol de Asistente educativo de los CREAP del SEAD.

\section{Objetivos}

- Compartir, con pares y docentes formadores, las inquietudes surgidas de una reflexión crítica sobre la situación actual de la formación universitaria con vistas a fortalecer los niveles de participación y compromiso que hagan posible emprender acciones transformadoras en los ámbitos de decisión y actuación personal.

- Analizar e interpretar los procesos de construcción del conocimiento en el nivel superior, redimensionando la incidencia, en ellos, de la intervención 
docente entendida ésta, desde la asunción del rol como sujeto de determinación curricular, hasta la mediación que se efectiviza en los procesos de transformación del conocimiento en cualesquiera de sus modalidades y en los entornos particulares que cada una de ellas demanda.

- Revisar las propias concepciones para fortalecer la toma de posición consciente y sólidamente fundamentada frente a las decisiones que entraña la intervención didáctica en consecución de mayores y mejores logros en la calidad de los aprendizajes de los estudiantes.

- Mejorar las competencias comunicativas y tecnológicas y actualizar la información institucional y el conocimiento de los circuitos administrativos con vistas a optimizar el desempeño de las funciones tradicionalmente asignadas al cargo como aquellas que pudieren presentarse en función de la adecuación del sistema a nuevos requerimientos institucionales y sociales.

\section{Propuesta pedagógica}

En atención a las necesidades detectadas en el proceso de evaluación diagnóstica se desarrollará el programa en ambas modalidades. De este modo se apela tanto a la riqueza de la presencialidad como a la potencialidad de la modalidad a distancia. En el primer caso con intención de brindar oportunidad de reforzar los lazos vinculares que caracterizaron las primeras etapas del sistema y en el segundo con el propósito particular de crear las condiciones que hagan posible desarrollar, desde la experiencia del usuario, las capacidades y destrezas comunicativas que exigen los entornos virtuales. En consecuencia se alternarán encuentros presenciales regionalizados con tramos de enseñanza a distancia a través del campus virtual.

Los primeros se dinamizarán a partir de una presentación digital y documentos impresos con orientaciones para la actividad grupal.

El campus virtual ofrece las siguientes secciones: contenidos, calificaciones, sitios, foros, calendario, agenda. En este mismo entorno se vehiculizarán las tutorías cuyas características y requisitos se expondrán en el diseño didáctico correspondiente a cada componente.

El programa tendrá una duración de dos años. Se prevé su aplicación en el bienio 2007 - 2008. Está constituido por tres componentes: didáctico, tecnológico e institucional administrativo. 
El Sistema de Educación Abierta y a Distancia de la Universidad Nacional de Mar del Plata...

De acuerdo con las cinco áreas institucionales -Producción Didáctica; Comunicación y Diseño; Administrativa; Tecnológica y de Investigación Evaluativa e Información Académica- el programa vinculará cada uno de sus componentes a una o varias de ellas, de manera de satisfacer las necesidades de formación y actualización del AE de forma abarcativa, integral y solidaria con los requerimientos de la nueva estructura interna del sistema.

El esquema destaca el propósito institucional en el que el programa se inserta, el propósito rector de la propuesta, una breve descripción de cada componente y la vinculación entre éstos y las áreas institucionales.

\section{PROGRAMA DE FORTALECIMIENTO, REDIMENSIONAMIENTO Y ACTUALIZACIÓN DEL ROL DE ASISTENTE EDUCATIVO DEL SEAD}

\section{PROPÓSITO \\ INSTITUCIONAL}

Generar, sostener, evaluar y mejorar una propuesta de oferta académica a distancia, tecnológicamente accesible, democrática, abierta, flexible, innovadora y de calidad que sirva para reposicionar a la UNMdP en este campo.

\section{PROPÓSITO}

DEL PROGRAMA

Favorecer la creación de ambientes de aprendizaje virtuales y presenciales para la reflexión crítica, el intercambio fructífero y la construcción individual de los saberes teórico-prácticos que garanticen el ejercicio idóneo del rol de Asistente Educativo de los CREAP del SEAD.

\section{O $O M \quad P \quad O \quad N \quad E \quad N$ T E S}

vincula con

Área Producción Didáctica Área Investigación Evaluativa

\section{2}

TECNOLÓGICO

Propone la revisión del saber pedagógico adquirido y la construcción de un saber enriquecido con los aportes de nuevos enfoques y desarrollos en didáctica del nivel superior y en los requerimientos propios del sistema de educación a distancia

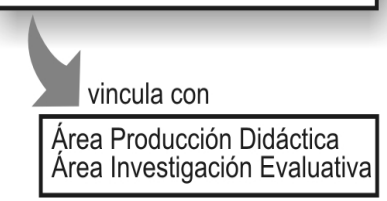

Tendiente a la capacitación en el manejo de las tecnologías comunicacionales vincula con

Área Comunicación y Diseño Área Tecnológica

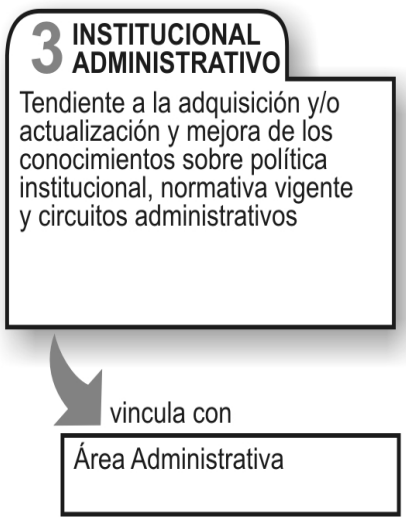


Por ser el componente didáctico el primero previsto para su implementación a partir de 2007 se transcribe seguidamente su diseño didáctico. Se señala en grisado el recorte seleccionado para su ejecución como prueba piloto, a través del espacio Enlace CREAP.

\section{Componente didáctico}

Trayecto base

Objetivo

Recuperar y resignificar los saberes construidos como referentes de teoría y empiria que brindan fundamento a la acción

Contenido organizador

Pensar la universidad; posicionarse como docente universitario

- Expansión y transformación de la universidad Argentina. ¿Democratización o exclusión?

- El problema de la calidad de la enseñanza universitaria. Controversias en torno a la calidad en la modalidad a distancia.

- La didáctica del nivel superior y el proceso de determinación curricular en la realidad universitaria. El docente universitario como sujeto de determinación curricular.

- Análisis y revisión crítica del proceso de transposición didáctica en el contexto particular de la enseñanza universitaria a distancia. Enclaves de transposición en la modalidad.

- Rol del asistente educativo en la concepción, diseño, ejecución y evaluación del Plan de Trabajo Anual.

Trayecto orientado a la potenciación del rol como docente-tutor

\section{Objetivo}

Deconstruir-reconstruir los saberes que sustentan la intervención estratégica en el proceso de aprendizaje de los estudiantes 
Contenido organizador

- Análisis y revisión crítica de diferentes aportes sobre el sistema y la acción tutorial.

- Efectos del contrato didáctico: las transformaciones del contenido en las interacciones discursivas sincrónicas o asincrónicas.

- Tensiones de la intervención tutorial: entre la negociación de significados y la vigilancia epistemológica. Alternativas didácticas promotoras del desarrollo de estrategias cognitivas para la conducción de sesiones de aprendizaje: diferentes abordajes para el análisis, interpretación, organización y comunicación de la información en ajuste con los diversos soportes en que se vehiculizan.

Trayecto orientado a la reflexión metacognitiva

\section{Objetivo}

Conocer e intervenir en el propio proceso de aprendizaje para modelar la intervención en el proceso de aprendizaje del estudiante.

Contenido organizador

Aprender a aprender; aprender a enseñar; enseñar a aprender.

- Los fundamentos y requisitos del aprendizaje. Marco teórico interpretativo del proceso de aprendizaje: revisión crítica de viejos y nuevos enfoques. Alcance didáctico de los fundamentos epistemológicos.

- Estilos cognitivos, estrategias de aprendizaje y metacognición. Evaluación del aprendizaje y autorregulación del aprendizaje.

- Fundamentos y finalidades de la evaluación en el nivel superior. Análisis de las modalidades evaluativas empleadas en las diferentes ofertas del SEAD. La evaluación como práctica metacognitiva: estatus de vector guía de los criterios e indicadores de evaluación.

\section{PALABRAS FINALES}

Tal como el título propone, el Área de Producción Didáctica se presenta en esta proyección a futuro, como el núcleo vital en el que se gestaron tres propuestas de fortalecimiento del Sistema. 
Nuestra trayectoria, también lo decíamos al comienzo, supo de avances y retrocesos, de esfuerzos resarcidos con la satisfacción de los logros alcanzados y de otros que no corrieron igual suerte. De unos y de otros hemos salido fortificados. Coincide esta comunicación con el término de un ciclo lectivo y esa es ocasión propicia para que crezcan las expectativas puestas en el año entrante.

Compartimos con la comunidad de colegas que conciben, gestionan, evalúan, reflexionan, y hacen verdadera praxis de la educación a distancia nuestro anhelo de que la modalidad gane cada vez más amplios sectores con el espíritu democrático que le es inherente y elimine definitivamente las barreras que separan a aquellos sectores con acceso al conocimiento de los que aún están marginados de él.

\section{NOTAS}

1 La Presentación Institucional tanto como la Estructura Organizativa que aquí se reseña, fue armada en base al documento institucional de presentación del sistema ante el Ministerio de Educación, Ciencia y Tecnología de la Nación Argentina, de acuerdo a su normativa 1717/o1 para la presentación de ofertas académicas universitarias con modalidad a distancia. Sistema de Educación Abierta y a Distancia - Universidad Abierta (2006) Selección, organización y edición de textos: Lic. Mariel Ruiz Duhalde y Prof. Margarita Argüello.

2 Anteproyecto Universidad Abierta (1986) Prof. Victoria Matamoro y colaboradores.

3 Pese a este imaginario institucional el Consejo Superior aprueba la Ordenanza $\mathrm{N}^{\circ}$ 424 del año 1985 estableciendo el Sistema de Educación a Distancia

4 A efectos de simplificar la información se consigna solamente el año de inicio de la primera edición de cada oferta académica.

5 Actualmente se ofrecen a través de nuestro campus virtual dos de ellos: Bases conceptuales y modelos organizativos en $\mathrm{EaD}$ y, la producción de un proyecto de $\mathrm{EaD}$

6 Los autores analizan el impacto, que en las universidades canadienses, han tenido los acuerdos NAFTA (Acuerdo del libre comercio norteamericano) y FTA (Acuerdo del libre comercio)

7 Se toman estas referencias de Oliva, G. (2004) Curso de Nivelación para aspirantes a ingreso a la FCA: Informe final.

8 Este curso ha tenido tres versiones metodológicas: 1997/1998. Material Impreso: Cuadernos de Trabajo (I y II), conteniendo las indicaciones metodológicas, la presentación y desarrollo de las temáticas convergentes, las orientaciones para el análisis y tratamiento de la información, las Actividades de Integración, las propuestas de trabajos prácticos, etc. 
El Sistema de Educación Abierta y a Distancia de la Universidad Nacional de Mar del Plata...

2001 CD conteniendo los cuadernos I y II, en formato pdf y lista de distribución electrónica. La realización en este formato nos permitió mantener el diseño de los cuadernos de trabajo como en su versión original y posibilitarle al alumno navegar por las diferentes partes del documento.

2004 Plataforma de e-learning: esta nueva versión del curso, conteniendo los cuadernos de trabajo, fue desarrollada para ser implementada en entorno web a partir de la construcción de herramientas pedagógicas y la utilización de herramientas tecnológicas adecuadas para dicho entorno.

Para ampliar información sobre curso y el equipo de trabajo responsable de la propuesta: http://ww.mdp.edu.ar/uabierta/acui/index.htm

9 Las acciones listadas corresponden a las diferentes áreas para dar idea de una secuencia integral. Las funciones y tareas comprendidas dentro del Área de Producción Didáctica se identifican con $(*)$

10 Este curso se concibió y efectivizó entre 1987/88 correspondiendo a la etapa fundante del sistema. Sus intenciones rectoras apuntaban al logro del perfil del Asistente Educativo como educador abierto consustanciado con los fundamentos y principios del sistema.

11 La Licenciada Adriana De Stefano fue la responsable del dictado del primero de los tópicos y tuvo a su cargo el seguimiento de las actividades durante las jornadas presenciales así como las tutorías, monitoreo y corrección de las propuestas de trabajo de los cursantes.

\section{REFERENCIAS BIBLIOGRÁFICAS}

Banno B.; De Stefano A. (2001). Los modos de intervención educativa en el diseño pedagógico de materiales. Revista Iberoamericana de Educación a Distancia, 4 (1).

Banno, B.; De Stefano, A (2004). Los materiales educativos y su puesta en escena en las estrategias didácticas. Revista Novedades Educativas, 16 (158).

Buchbinder, H.; Rajapogal, P. (1996). Universidades canadienses: El impacto del comercio y la globalización. Higher Education, 31, 283-299.

Cabezas, M.; Mariano, C.; Oliva, S.; Oliva, G. (2001). New Technologies Applied to Training. Evaluation of a New Teaching
Methodology for the Descriptive Geometry. ECAADe, 19. Helsinki: Helsinki University of Technology.

De Stefano, A; Banno, B.; Oliva, G. (2004). Apuntes para innovaciones curriculares en el nivel universitario. Revista Universidades. México, UNAM, 27.

Fainholc, B. (1999). La interactividad en Educación a Distancia. Buenos Aires: Paidós.

García Aretio, L. (2001). La educación a distancia. De la teoría a la práctica. Barcelona: Ariel.

Litwin, E. (2000) La educación a distancia. Temas para el debate en una nueva agenda educativa. Buenos Aires: Amorrortu. 
Lugo, M. T.; Schulman, D. (1999). Capacitación a distancia: acercar la lejanía. Buenos Aires: Magisterio del Río de la Plata.

Pozo, J I.; Monereo, C. (eds.) (1999). El aprendizaje estratégico. Madrid: Santillana.

Oliva, G. (2002). Un nuevo rumbo para la Educación a Distancia. En AAVV $L a$ producción de un proyecto de educación a distancia. Disponible en www.mdp. edu.ar/uabierta/ead.

Oliva, G.; Troglia, M. (2003). Acerca de las estrategias. Revista Alternativas. Facultad de Humanidades y Ciencias de la Educación - UNSL, 30.

Oliva, G. (2004). Estilos cognitivos y estrategias de aprendizaje: una cuestión prioritaria en la gestión del ingreso a la Universidad.QuadernsDigitals.Segunda parte. Monográfico sobre Educación a Distancia. [en línea] Disponible en: http://www.quadernsdigitals.net [consulta 2006, 7 de febrero]

Sandoval, S. A. (2003). Una visión de conjunto y un acercamiento práctico a la enseñanza del pensamiento. [en línea] Disponible en:http://educacion.jalisco. gob.mx/consulta/educar [consulta 2006, 7 de febrero]

Santangelo, H. (2000). Modelos pedagógicos en los Sistemas de Enseñanza no presencial basados en Nuevas tecnologías y Redes de comunicación. Revista de la Organización de Estados Iberoamericanos, 24. [en línea] Disponible en: http://www.campusoei.org/revista/rie24a06.htm [consulta 2005, 7 de febrero]

\section{PERFIL ACADÉMICO Y PROFESIONAL DE LAS AUTORAS}

BeatrizGraciela Banno,licenciadaCiencias delaEducación(1981). Especialización en EaD, (1984-85). Postgrado en área de Teleformación -Universidad de Sevilla. (2000) Diploma Superior en Ciencias Sociales, orientación Educación - FLACSO(2004). Docente UNMdP, desde 1984.

Consultora en Diseño Curricular por Competencias. Programa FONIT-PRESTNU, Ministerio de Educación, Ciencia y Tecnología de la Nación - ITEC Miramar (2001o6).

Investigadora categorizada. Grupo de Investigación Cognitiva y Educacional (GIPCE) Facultad de Psicología.

E-mail: bbanno@mdp.edu.ar

Guillermina Oliva, Licenciada en Ciencias de la Educación, Psicopedagoga Clínica y Máster en Educación Ambiental. Docente UNMdP desde 1979. Profesora Titular del SEAD desde 1987. Actualmente coordinadora pedagógica del Curso de 
ingreso a la FCA. Es autora y responsable de la implementación del Programa de fortalecimiento, redimensionamiento y actualización del rol de asistente educativo.

Investigadora categorizada. Autora de libros y artículos en las especialidades de Educación Ambiental y Teoría y diseño curricular.

E-mail guioliva@infovia.com.ar / guillermina-oliva@hotmail.com

DIRECCIÓN DE LAS AUTORAS

Beatriz Graciela Banno

Ángel Roffo 2295 -

CP7600 - Mar del Plata, Argentina

Guillermina Oliva

XX de Septiembre $26804^{\circ} \mathrm{A}-$

CP 7600 - Mar del Plata, Argentina

Fecha de recepción del artículo: 20/12/06

Fecha de aceptación del artículo: 22/02/07 